\title{
An analysis of the determinants in Economics and Business publications by Spanish universities between 1994 and 2004
}

\author{
Raúl Ramos $^{\mathrm{a}}$, Vicente Royuela ${ }^{\mathrm{b}}$, Jordi Suriñach ${ }^{\mathrm{c}}$ \\ AQR Research Group - IREA. University of Barcelona
}

\begin{abstract}
Summary: The objective of this study consists, firstly, of quantifying differences between Spanish universities' output (in terms of publications and citations), and secondly, analysing its determinants. The results obtained show that there are factors which have a positive influence on these indicators, such as having a third-cycle programme, with public financing obtained in competitive selection procedures, having a large number of full-time researchers or involvement in collaborations with international institutions. However, other factors which appear to have the opposite effect were also noted. These include a higher number of students per lecturer or a lower proportion of lecturers with recognised six-year periods.
\end{abstract}

Keywords:

Bibliometric techniques, scientific production determinants, count data models, censored data models.

Corresponding author. Departament d'Econometria, Estadística i Economia Espanyola, Universitat de Barcelona, Avda. Diagonal 690, 08034 Barcelona. Tel.: +34+934024310. Fax: +34+934021821. E-mail: rramos@ub.edu

b Departament d'Econometria, Estadística i Economia Espanyola, Universitat de Barcelona, Avda. Diagonal 690, 08034 Barcelona. Tel.: +34+934021012. Fax:+34+934021821. E-mail: vroyuela@ub.edu

c Departament d'Econometria, Estadística i Economia Espanyola, Universitat de Barcelona, Avda. Diagonal 690, 08034 Barcelona. Tel.: +34+934021980. Fax: +34+934021821. E-mail: jsurinach@ub.edu 


\section{An analysis of the determinants in Economics and Business publications by Spanish universities between 1994 and 2004}

\section{Introduction and objectives}

In recent years, various studies have shown the significant increase in publications by Spanish authors in international Economics and Business journals during the first half of the 1990s. This led to an improvement in the relative position of Spanish economic research in international terms, and it has gradually come closer to the level of excellence attained in other disciplines. As a result, Spanish research occupies ninth place in the Institute for Scientific Information (ISI) report for the period 1995-2005 in the ranking of articles published and twelfth place for citations, while as regards research of a strictly economic nature, it holds eighth position in terms of articles and eleventh for citations. ${ }^{1}$

Another aspect that has also been observed is the significant differences between the results obtained by the various universities in economic research. These differences are more clearly marked than in other disciplines (Moya-Anegón, 2005), and this is the main reason to focus on the determinants of differences in scientific production in this field. The first area in which this evidence can be found is in works financed by the European Economic Association ${ }^{2}$ in order to establish rankings for European institutions and compare their relative position with that of American institutions. One of these works is that by Coupé (2003), which presents rankings of authors and institutions based on all the publications which are part of the Econlit database for the period 19941998. According to this author, there are thirteen researchers affiliated to Spanish institutions among the top thousand researchers worldwide, and there are only four Spanish institutions among the world's top two hundred institutions internationally. Another work on this subject is by Kalaitzidakis et al. (2003) which also establishes rankings for the same period, but uses the 30 best economics journals and the citations from previously published articles received in 1998. According to this study, there are four Spanish institutions among the best two hundred internationally, and of the top 120 European institutions, six are Spanish., Bauwens et al $(2000,2002)$ establish rankings based on a productivity index for institutions, with ten Spanish institutions in the top 152 in Europe. When they limit the sample of journals considered to the 67 most important, the total number of institutions falls to 92 $(40 \%)$ and the number of Spanish institutions falls to 6 (by the same proportion). ${ }^{3}$ Finally, Tombazos (2005) establishes rankings for two subperiods, 1991-1996 and 1997-2002, from articles in the most 30 frequently cited journals in Economics. According to his results, only eight Spanish institutions

\footnotetext{
${ }^{1}$ http://www.in-cites.com/countries/2005allfields.html and http://www.in-cites.com/countries/top20eco.html.

2 http://www.eeassoc.org.

3 Other works financed by the EEA are those by Lubrano (2001) and Combes and Linnemer $(1999,2000)$. The former establishes rankings within each country for institutions in Belgium, France and Spain, while the latter two focus only on analysing the economic research situation in France.
} 
appear among the first two hundred institutions in the first subperiod, while in the second, five Spanish institutions appear in the first fifty positions. Some of them were not Universities but other research institutions such as the Institut Anàlisi Econòmica (CSIC) or the CEMFI.

There is also another series of papers with greater emphasis on exclusive analysis of the economics research situation in Spain. Among these studies are those by García et al. (1999a), García et al. (1999b), Sanz et al. (1999) and Villar (2003). Their conclusions are similar to those presented above. However, the studies by Martínez Cabrera (2000) and Bergantiños, Da Rocha and Polomé (2002) present an interesting new feature, as they focus on in-depth analysis of productivity rather than production or its impact. The former goes into depth as regards the knowledge of production technology of higher education institutions, and obtains empirical results for the technical efficiency of a sample of Economics departments in Spanish public universities during the period 1994-1995. The methodology used is based on the linear programming techniques provided by Data Envelopment Analysis and its results show that there is a significant margin for potential improvement in the productive output of the departments analysed. The latter confirms the increase in scientific production in the Economics field in Spain during the period 1995-1999. It also confirms the difficulty of measuring the size of the centres responsible for the research, something which does prevent it from providing a result which indicates that research in Economics is very concentrated, ranging from institutions with a presence in European and international rankings to others that have not published a single article in journals included in the Social Science Citation Index (SSCI), elaborated by ISI. Furthermore, two of the leading institutions in its final ranking are not universities but are instead research centres, which despite their small number of researchers have a much higher volume of research than the majority of public universities.

Taking these two background factors into account, the objective of this work study is firstly to obtain a measurement of the production, its impact and of the scientific productivity of Spanish universities in the field of Business and Economics research for the period 1994-2004. Bibliometric techniques are applied in order to obtain these measurements. Secondly, in order to identify the determinants of the differences noted between institutions, the most appropriate econometric techniques are applied to check the explanatory capacity of a whole range of factors, which are mentioned in the international literature and specific to Spanish universities for these measurements.

The remainder of the study is divided into in three sections. Firstly, there is a review of the limited literature on the subject. The results of the work related to the two objectives mentioned above are then presented. Finally, the study concludes by listing the main conclusions of the analysis carried out. 


\section{Review of the literature}

Taking the background factors mentioned in the previous section on scientific production in Economics and Business by Spanish universities into account, in this section we will focus on gathering the evidence available regarding the determinants of scientific production and productivity in the Economics and Business' university context ${ }^{4}$.

Although bibliometric analysis on Business and Economics were already published during the fifties and sixties of the last century ${ }^{5}$, it must be stressed that only a few studies have analysed the specific determinants of scientific production in this field. To the best of our knowledge, the first paper to analyse this aspect is Graves et al. (1982). Combining publications data and information obtained through a survey to the US university departments, they find that secretaries per faculty member, ph. D. granting institutions, teaching loads and teaching assistance, student/faculty ratios, and support services clearly affect the scientific production of economists.

Following a similar methodology, Dusansky and Vernon (1998) find that the factors explaining differences in production and productivity between departments are the professional category, length of time in the post, hours worked and the students' opinion, among others. However, the main objective of this study was to analyse the differences between the different rankings and the factors which explained these differences.

Based on this paper, other authors have extended this line of research to consider the role of other factors which may influence scientific production and productivity. For example, Fox and Milbourne (1999) look at the characteristics explaining research productivity in a sample of 150 economists. Their results suggest that human capital variables, such as the nature and location of the Ph.D. are specially relevant, but teaching loads are also statistically significant. However, perhaps the most extensive study using survey data is that by Maske et al. (2003). Using the data from a survey, these authors analyse the determinants for the articles published by 1000 lecturers who were members of the American Economic Association in 1989. Their results show that production varied according to their teaching loads, the research orientation of the institution to which they belong, their years of experience and teaching at higher levels (third cycle). They found that race had no influence on production, although they did find significant differences by gender.

Some aspects not considered by Maske et al. (2003) were the role played by the departments' and/or researchers' obtaining of additional financing for scientific production. In this regard, Huettner and Clark (2001) mentioned the importance of the public financing received by departments (and obtaining aid in competitive selection procedures in particular) as one of the most relevant factors in

\footnotetext{
${ }^{4}$ As stated in the previous section, this paper focuses on Economics and Business research and, for this reason, the review of the literature will only include references on this field. However, there is a vaste literature analyzing the determinants of scientific productivity in the natural and medical sciences: see, for example, Ehrenberg (2003) for an excellent survey or Adams and Clemmons (2006) for an applied study of US universities.

${ }^{5}$ See, for example, Fusfeld (1956).
} 
explaining differences in scientific production. However, Johnes (1988), Spangenberg et al. (1990a, 1990b), Faria (2001) and Taylor et al. (2006) also highlight the negative influence of participation in consultancy studies on scientific production (private funding).

Another interesting study which complements the one by Maske et al. (2003) is by Davis et al. (2001). These authors analyse the productivity of a cohort of economists during the fifteen years after producing their doctoral thesis. Their results conclude that it is not true that the dissemination of research using journals or books are alternative channels, but instead that those who publish the most articles are also those who publish the most books. Those who publish the most articles are those who teach at the highest levels and who produced their doctoral thesis on subjects of a general nature or who applied quantitative methods. An interesting additional result was that production starts to decline once they achieve professional stability. A similar result was obtained by Mein (2002). This author found that in departments in which the promotion of researchers depends on their scientific production, there is a positive correlation between the production of the department as a whole and the percentage of researchers awaiting promotion.

Kalaitzidakis et al. (2004) analyse the factors determining research activities in a selection of Economics departments in European universities between 1993 and 1998. The source used is a survey carried out in these departments which requested information on the average salary, the age of the department, the number of students, the existence of a doctorate programme and the existence of a range of working documents, as well as the existence of active links with other universities in the United States. Using a regression analysis, these authors found that the most important factors are department size (students), time in the post and the existence of international contacts.

Cherchye and Vanden Abeele (2005) analyse Business and Economics research "micro-units" at Dutch universities in order to analyse the patterns of this research and the impact of its size and external financing received for it. Their results show that there is a positive relationship between the efficiency of academic research and the amount of external financing that it receives.

We also feel that the factors which can be considered specific to our environment and which may determine the Spanish universities' process of scientific production must be assessed. In general, the policies adopted by public agents in terms of scientific policy are essentially policies for assigning resources (which are generally scarce) among the various actors in the system. On the one hand, the aim is to give the system legitimacy by an analysis of the quality or of the excellence of the research done by the actors. However, it must be acknowledged that in recent years, governments have identified the benefits of scientific policies applied to the growth of the economies in which they are implemented. Science as a motor for growth consequently plays a major role. In this respect, as well as the assignment of resources being legitimised by the excellence of the science taking place, there is also the legitimisation of resources assignment by the expected effects of economic growth. These two views of scientific policy lead to two models - academic and business - being considered. These will direct resources towards the promotion of academic research or to the process of technological 
innovation, which are aspects that usually take place in different places - universities and companies, respectively. In this respect, it may be assumed that the institutional-based approach may explain part of the scientific production of Spanish universities, with institutions considered as the actors' range of rules and incentives structure. It is also acknowledged that universities have experienced a transformation in the missions entrusted to them by society, ranging from teaching in its strictest sense, to research and, finally, the transfer of technology, which is dealt with in article 11 of the University Reform Law (URL) of $1983 .^{6}$

The availability of resources from public funds (regional, national or international) must also be considered as incentives to research (Sanz Menéndez, 2003). Having resources to carry out research enables the researcher receiving this aid to show the "feasibility of his/her ideas" and at the same time, to obtain greater recognition from the system for the evaluation of research done by the public system.

As a result, having financing enables the researcher firstly, to confirm his/her own research, while demonstrating the feasibility of the theories, thereby reinforcing this line of research, which leads to a general process of self-confirmation of the dominant positions in science. Being the first to make a discovery and obtain peer recognition are vital aspects in research careers. Reputations are thus obtained by communication and publication of results and their subsequent "quotation". However, like the research itself, the processes for the dissemination of these results require financial resources, which in terms of basic science are associated with competitive processes in which recognition or "credibility" plays a key role. As a result, according to Sanz Menéndez (2003), "the cycle of traditional credibility established by means of a cognitive connection between production, communications and collective assessment of results is extended by their inclusion in the processes of competition for public funds to be able to continue the research". This competitive system for obtaining financed public projects allows the excellence of the research done to be accredited by the appropriate bodies, as it has been assessed ex ante by an anonymous committee in a competitive selection procedure. ${ }^{7}$

As a result, based on a review of the literature, the proposed model for analysing the potential determinants of scientific production and productivity of Spanish universities is as follows:

$$
Y_{i j}=\beta_{0}+\beta_{1} \cdot X 1_{i}+\beta_{2} \cdot X 2_{i j}+\beta_{3} \cdot X 3_{i j}+U_{i j}
$$

where $Y_{i j}$ is a measure of the scientific production or productivity of university $i$ in the field $j$ (Economics and Business), $X 1_{i}$. includes all the characteristics of the university which may influence this production (public or private ownership, year of creation, number of degrees and diplomas, number of students, type of lecturers, number of lecturers, tenured staff / non-tenured staff, distribution of lecturers by gender, average age, lecturers with recognised six-year research periods, external researchers employed (e.g. through the Ramón y Cajal programme, etc.), $X 2_{i j}$ includes all the

\footnotetext{
${ }^{6}$ This article was replaced by article 83 of the Constitutional Law of Universities (CLU) of 2001

${ }^{7}$ For an analysis of the state of assessment of research in Spain, see Sanz Menéndez (1995).
} 
characteristics of the area of analysis considered, i.e. of Business and Economics studies in the field of teaching for each of the universities analysed (number of students registered, number of third cycle students, etc.), $X 3_{i j}$ also refers to the Business and Economics field but in terms of research (for example, the number of theses read in this field, the number of public projects obtained in this area or participation in research European programmes), and finally $U_{i j}$ includes all the non-observable characteristics which also influence the variables analysed.

\section{Empirical evidence}

This section presents the empirical evidence relating to measurement of the research done between 1994 and 2004 by researchers affiliated to Spanish universities in the Business and Economics field, and its determinants. Firstly, there is a description of the procedure used to produce the database necessary to carry out the study. The results relating to the different indicators of the research done which have been produced are then presented, and finally, the evidence relating to the analysis of the factors determining the differences between universities in terms of the scope of this research are presented.

\subsection{Production of the database}

\subsubsection{Identification of universities for analysis}

Because the objective of this study is to obtain a measurement of productivity for Spanish universities in the field of research in Economic and Business Sciences, it is first necessary to identify which universities will be subject to analysis. We have decided to analyse the universities which during the period under consideration (the academic years between 1994/1995 and 2004/2005) taught officially approved courses in Economics or Business Administration and Management. ${ }^{8}$ Table 1 shows the public universities that taught these courses in the academic year 2004/2005, while tables 2 and 3 respectively show the same information but for the private universities of the Catholic Church and the other private universities.

TABLES 1,2 and 3

\footnotetext{
${ }^{8}$ If we had expanded the list of studies to include second cycle Market Research and Techniques and Actuarial and Financial Sciences degree courses, there would have been no change in the universities selected. Taking the Business Sciences Diploma into consideration would only have entailed consideration of the Polytechnic University of Catalonia and of the Miguel de Cervantes European University. It was decided not to include the former in the study due to the relatively low level of importance of this qualification in the work of the university. In specific terms, the course is taught at two University Schools - the Caixa d'Estalvis de Terrassa business school and the Administración de Empresas Winterthur business school, which are attached to the university. The latter is a centre in its own right but its recent opening also suggested that its inclusion in the analysis would be unwise.
} 
Table 4 shows a synthesis of the relative importance of Business and Economics studies in the Spanish university system. Of the 72 universities currently operating in Spain, 39 offer Economics studies and 65 offer Business Administration and Management Studies. All those that offer Economics studies also provide Business Administration and Management. As a result, and taking into account that the San Vicente Mártir Catholic University of Valencia, the Abat Oliba C.E.U. University and the Mondragón University have been excluded due to their recent creation as far as the qualifications analysed here are concerned, the list of universities to be considered in the analysis comprises these 62 universities.

\section{TABLE 4}

\subsubsection{Bibliometric information}

Bibliometrics consists of the application of mathematical and statistical methods to measure the qualitative and quantitative changes that arise in scientific publications. By using this type of quantitative technique, it is possible to analyse the profile of publications by academic institutions or the authors in certain journals. They are used to measure the importance of different subjects or areas of research in the main scientific publications or to analyse the evolution of research in a given country.

It should first be pointed out that taking the objective of the work into account, it was decided to limit the analysis to publications by lecturers and/or researchers affiliated to the various university centres (public and private) located in Spain which taught approved Economics and/or Business courses during the 1994-2004 period.

As Conroy and Dusansky (1995) point out, there are three methodological aspects that must be considered when a bibliometric study is being designed:

i. The first consists of selecting the journals on which the analysis will be based,

ii. The second aspect is to determine what the unit of measurement to be used will be (how should scientific production be measured?), and

iii. Finally, the third aspect is that some types of analysis may require information that is not in the normal bibliographical databases ${ }^{9}$ such as the author's country of origin, for example.

\footnotetext{
${ }^{9}$ An additional point that is worth stressing is how the author's country is identified. This may be done using the country of the institution to which the author is affiliated when the article was produced. This means that possible subsequent changes of institution are not included, and nationality is not considered, i.e. all researchers working in a Spanish institution regardless of their nationality are deemed to be "Spanish" in this analysis, and Spanish researchers working in a foreign institution are not considered "Spanish". An alternative option would have been to use a list of 4,695 researchers attached to Spanish universities and ascertain their publications using the various bibliographical databases. However, this type of search would not take the possible changes in researchers' affiliations to various institutions into account.
} 
How these three aspects were resolved in this study is shown below.

\section{A. Selection of the journals and articles for analysis}

In order to carry out the proposed analysis, the range of internationally renowned journals in which Spanish authors can publish their works in the field of Economic and Business Sciences was analysed.

A first option would have been to consider the publications included in the Econlit database. ${ }^{10,11}$ However, a limitation of this database is that it does not allow the number of citations received by each of the articles considered to be analysed, which as we will see is clearly relevant information.

However, it is possible to obtain this information for the publications included in the Social Science Citation Index (SSCI) database, ${ }^{12,13}$ although we have to recognise that this choice implies assuming additional limitations or caveats apart from the ones already mentioned.

In particular, it is important to highlight that we will consider all publications included in the areas of demography; management; economics; business; business and finances; environmental studies; geography; history; planning and development; industrial relations; and urban work, transport and studies. This implies that a publication by a member of the staff of the considered universities in a journal not included in these areas will not be taken into account. The alternative of analysing individual authors in order to consider all possible publications and not just the ones that we consider as "business administration and economics" publications, will necessarily imply to carry out timeconsuming manual corrections of the different possible spells of authors names and to perform several searches in the database.

Moreover, the SCSI covers only a segment of the journals published in each discipline. As reported by Cameron (2005) it was estimated that in 1997 the Science Citation Index covered a mere 2.5 percent of the world's scientific journals. ISI argues that it indexes in the Web of Science those journals that are known to be of high quality and that have influence and impact, but the criteria are not clear. However, as pointed out by Verbeek et al. (2002), the SSCI is currently by far the most commonly used source worldwide for comparative bibliometric analyses of disciplines and faculties in the field of economics and social sciences and for this reason, it is used in this paper and, as usual, in

\footnotetext{
${ }^{10}$ The Econlit database has five disadvantages when used for bibliometric purposes. Firstly, the information on the names of authors and institutions is not standardised (this problem especially affects the production of rankings). Secondly, when an article is signed by more than three authors, the information for only the first author appears (thus if any author affiliated to a Spanish institution has published his/her work in collaboration with more than 2 authors and does not appear in first position, this article will not be included in our analysis). The third problem is that only partial information is available for some journals (not all the years are included). The fourth is that the authors' affiliation is only available since the late 1980s. Finally, there is an English-speaking bias: i.e., English-language journals are over-represented.

${ }^{11}$ www.econlit.org.

${ }^{12}$ The SSCI also has the first, third and fifth disadvantages mentioned in footnote 10 for Econlit.

${ }^{13} \mathrm{http} / / /$ www.isinet.com/isi/products/citation/ssci/index.html.
} 
bibliometric studies, only those articles which have undergone a process of anonymous evaluation as a requirement prior to publication have been considered. For this reason, book reviews, commentaries, notes etc., which have not undergone this process are not included in the analysis.

The information concerning the publications and citations received by each of the articles by authors affiliated to Spanish universities was obtained by means of the ISI Web of Science database (which is part of the ISI Web of Knowledge database, to which we have access by means of a subscription financed by the Ministry of Education and Science).

\section{B. Analysis Unit}

As mentioned above, another aspect for consideration is what the unit of measurement to be used during this study should be. In bibliometric studies, it is normal to use the number of articles or the number of pages per article. If the number of articles is used as a criteria, the same importance would be assigned to articles of different lengths. As a result, and considering that editors have a limited number of pages per volume and volumes per year, it seems reasonable to assign the highest (lowest) number of pages possible during the evaluation process to articles of the highest (lowest) quality. As a result of all the above factors, the number of pages in the articles published could be an indicator of the quality of scientific production. However, it is also important to take into account the differences between page formats in the various journals, as failure to do so would lead to inappropriate comparisons being made. For this reason, it is necessary to carry out a standardisation process enabling these comparisons to be made, taking the number of characters per page in some of the journals considered as a benchmark unit. It should also be pointed out that carrying out the page standardisation process makes it necessary to consider any change in the format of the journals which may affect this process. As a result, this process would be so complex that in practice it is normally unfeasible.

Another way of assessing the quality of the articles (which would also include their impact) would be the number of citations received. This information is available in the database used, although a disadvantage is that the more recent articles will possibly have received fewer citations than older ones, despite being of higher scientific quality. This should be taken into account when interpreting the results of the following sections. 


\section{C. $\quad$ Other points of interest}

An additional question worth mentioning with regard to the design of the bibliometric study is that of co-authorships, i.e. articles written by more than author. The standard procedure in the literature consists of assigning each author the number of citations received by each article multiplied by $1 / \mathrm{n}$, where $\mathrm{n}$ is the total number of authors (Coupé, 2003). A similar procedure is applied in cases where the authors are linked to more than one institution (Kalaitzidakis et al., 2003). In this study, despite the fact that the procedure above is the most frequently used in bibliometric studies, it was decided not to weight according to the number of authors or due to the fact that an author may be affiliated to more than one institution. Our reasons for this decision are related to the fact that we are not going to produce rankings of authors, but instead of institutions and therefore what is of interest to us is ascertaining how many citations the articles published by authors affiliated to a specific institution have received. As regards various affiliations, in the Spanish university system it is practically impossible for an author to be affiliated to more than one university. He/she may be affiliated in a secondary manner to a foreign centre or to a specific studies service, but in neither of these two cases would these institutions appear in the rankings shown below.

\subsubsection{Other information}

As mentioned above, it will also be necessary to obtain information on the potentially explanatory variables for scientific production and productivity for Spanish universities. These variables included information on aspects related with characteristics of the university (public or private ownership, year of creation, number of degrees and diplomas, number of students, type of lecturers, number of lecturers, tenured staff/non-tenured staff, distribution by gender, average age, lecturers with recognised six-year research periods, external researchers employed through the Ramón y Cajal programme), the characteristics of the field of analysis under consideration, i.e., Business and Economics studies (the number of students registered, number of third cycle students) and of the research inputs (the number of theses read in the Business and Economics field, the number of public projects obtained in this field or participation in European research programmes).

As a result, it was also necessary to compile statistical information on each of these variables for the series of universities selected. To that end, we first consulted the publications on the websites of the Ministry of Education and Science, the Council of Universities, the Universia universities portal, the National Statistics Institute (INE), the Vice-chancellors' Conference (CRUE), the TESEO database for doctoral theses and the European Commission for participation in European projects (CORDIS). However, although there is a great deal of information available from these sources, in some respects it was insufficient for the purposes of the study, and was complemented by means of 
direct enquiries to the administrative bodies of each university. For reasons of space, we have not reproduced the database prepared in this study, although it is available on request to the authors.

\subsection{Production, productivity and citations received}

Using the databases analysed, between 1994 and 2004 researchers affiliated to Spanish universities published a total of 2,309 articles, of which 1,204 articles were quoted during the study period. In specific terms, the total number of citations received was 7,699 . This means that $52.1 \%$ of articles receive citations, and that 3.33 citations per article published and 6.39 citations per article quoted are received.

The total ratio of citations per article published in the economics field for the period January 1995 - April 2005 (and for the series of countries) is 4.73. The data for Spain according to the same source, ${ }^{14}$ is 2.84 (similar to 3.33 for the period 1994-2004). This means that the quotation of articles associated with Spanish universities is still a long way from the international average, led by the United States of America (6.23), Israel (5.27) and Hong Kong (7.41). If the number of publications and the number of citations received per article for the top five countries generating production of articles is analysed, and we compare them with Spain, we find that the United States publishes 61,408 articles and has a quotation rate of 6.23, for England the figures are 14,676 and 4.33, for Canada 7,147 and 4.32, for Germany 4,544 and 2.64, for Australia 4,377 and 2.8, and for Spain the figures for quoted articles are 2,526 and 2.84. A relevant point is that the only countries with a higher level of scientific production in economics than Spain (in the database analysed) are the United States of America, England, Canada, the Netherlands, France, Australia and Germany.

As mentioned above, it was decided not to divide these figures according to the number of participating co-authors when assigning each of the articles published and the citations received to each of the universities. As a result, the 2,309 articles obtained from the initial database became 2,631 occasions on which an author affiliated to a Spanish institution participated in the production of an article published in the journals considered, while the number of citations received increased from 7,699 to 8,329 . Table 5 shows the distribution of both variables for the variables analysed and the number of articles relativised by the average number of lecturers in the period analysed and the number of citations per article.

\section{TABLE 5}

As can be seen in the Table, the five most productive universities during this period were the Pompeu Fabra University, the Carlos III University, the Autonomous University of Barcelona, the

\footnotetext{
${ }^{14}$ Own calculations based on publications and citations in the SSCI database (ISI Web of Knowledge) in July 2005.
} 
University of Valencia and the University of Alicante, which published over 140 articles. These are followed by the Complutense University of Madrid and the University of Barcelona, with a very similar rate of production. As far as citations are concerned, the relative positions are very similar to those above, and of particularly note is the relative improvement of the University of Barcelona (rising to fourth position) and the inclusion in these leading positions of the University of the Basque Country (Euskal Herriko Unibertsitatea). However, the most interesting result from our point of view is the existence of major differences between the universities, regardless of the indicator analysed (although the fact that some of the universities considered were established after the beginning of the analysis should be taken into account). Figure 1 shows the Lorenz curve for the number of articles published and the number of citations received. The degree of concentration noted for both variables is very high. The Gini index for the number of articles is 0.68 , while for the number of citations it is 0.81 . In fact, $10 \%$ of the most productive universities account for over $40 \%$ of the articles and almost $70 \%$ of the citations. The objective of the next section will be to identify some of the determinants of these differences.

\section{FIGURE 1}

\subsection{Analysis of determinants}

Using the information given in the previous section, the objective of this section is to analyse which of the variables identified in the international literature contribute to explaining the differences in the production and impact of publications by researchers affiliated to selected Spanish universities. To that end, first the data count and censored data models are described, which are those which are the most appropriate taking into account the nature and the skewed distribution of the endogenous variables considered - the articles published, the articles published by lecturer, the total number of citations received and the average number of citations per article.

\subsubsection{Econometric methodology: models for data counts and censored data}

In the data count models, the dependent variable for each individual in the sample or population analysed is a whole number $(0,1,2, \ldots)$ which represents the count of the number of times that an event occurs in a given unit of time. Due to the discrete nature of the variable (apart from the abundance of zeros which usually characterises this type of data), a standard regression model based on the assumption of normality is clearly inadequate.

A specification which takes into account the discrete nature of the count is the Poisson data regression model, which assumes that each value taken by the variable $y_{i}$ is the production of a random variable $Y_{i}$ with a Poisson distribution of parameter $\lambda_{i}$ 


$$
P\left[Y_{i}=y_{i}\right]=\frac{e^{-\lambda_{i}} \lambda^{y_{i}}}{y_{i} !} y_{i}=0,1,2, . ., i \quad i=1,2, \ldots, N
$$

where by analogy with the regression model, it is assumed that $\ln \left(\lambda_{i}\right)=X \cdot \beta$. An important assumption of this model is that $E\left[y_{i} \mid x_{i}\right]=\operatorname{Var}\left[y_{i} \mid x_{i}\right]$. However, the phenomenon of overdispersion is very frequent, meaning that variance is greater than expected. In this case, the standard errors arising from the Poisson estimation model will be "too small," with the consequences for testing the hypothesis that would arise from this problem. However, there are various procedures which enable this problem to be detected and corrected, among which is the use of alternative distributions such as the negative binomial.

However, the problem that arises when the dependent variable is censored is that there is an accumulation of observations on the dependent variable at the censorship point. This accumulation may arise as a consequence of the procedure used to gather the data but also as a consequence of the process for generating data for the variable analysed.

The problem with the classic regression model in this context is that it is unable to explain the qualitative difference between limit observations (in our case, those assuming a value of zero) and non-limit observations. This means that estimations using OLS produce biased and inconsistent estimates. In fact, the seriousness of the problem increases with the number of limit observations. In this case, the idea is that the limit observations "would drag" the regression line downwards and to the left, leading to a bias in the estimated coefficients towards zero. An alternative would be to decrease the data (i.e. by removing the censored observations from the analysis) but this would not solve the econometric problem and would raise doubts as to the objective of our study.

An important aspect is that when the dependent variable is censored, the data include both discrete and continuous observations and their distribution therefore includes two components, a "mixture" of a discrete and continuous distribution. In order to analyse this type of data, the normal procedure consists of defining a latent variable associated with these observations, which is defined as follows:

$$
y_{i}=\left\{\begin{array}{ccc}
0 & \text { if } & y_{i}^{*} \leq 0 \\
y_{i}^{*} & \text { if } & y_{i}^{*}>0
\end{array}\right.
$$

This type of model is known as the Tobit model and solves the problems mentioned above with the normal approach using ordinary least squares (bias and inconsistency). This econometric methodology has also been used recently in a similar context by Taylor et al. (2006). 


\subsubsection{Results}

The results of using data count models to estimate the proposed model in (1) for the publications produced and citations received are shown below, followed by the results of using censored data models to estimate the same model for the number of articles per lecturer and the average citations per article. Models are thereby presented for four endogenous variables, in which two different samples have been used for each one. The first sample includes all the universities selected for the study, while the second sample includes only the public universities, as these have a much greater volume of information available in terms of possible determinants of production and impact.

Table 6 shows the results of the estimation of the different models for articles published, Table 7 shows the results for the models for the articles published by lecturer, while Tables 8 and 9 show the results for the estimated models for the number of citations received and the number of citations per article, respectively.

\section{TABLES $6,7,8$ and 9}

Looking at the results in the four tables, it can be seen that there is some degree of coincidence between the factors explaining both production, production per lecturer, the citations received and the impact of publications produced, with the variance proportion the various endogenous variables also being quite high. $\mathrm{R}^{2}$, or pseudo- $\mathrm{R}^{2}$ depending on the model, assumes values of over $60 \%$, and in several cases exceeds $90 \%$.

Something that should be taken into account in Poisson models with regard to the number of publications and the number of citations is the impossibility of the characteristic of Poisson distribution consisting of the variable coinciding with its variance value being fulfilled. If it is not fulfilled, i.e. when the value of the variance is significantly higher than the anticipated value (overdispersion), the estimation of this type of model should be performed for maximum verisimilitude by assuming a negative binomial distribution for the endogenous variable, thereby allowing for the possibility of the anticipated value and the variance being different. For this reason, the overdispersion tests proposed by Cameron and Trivedi (1990) and Wooldridge (1990) have been applied in order to check on the existence or otherwise of overdispersion in the data analysed. ${ }^{15}$

\footnotetext{
${ }^{15}$ The test proposed by Cameron and Trivedi (1990) has the Poisson model being the most appropriate one as a null hypothesis. The procedure for performing the test consists of first estimating this model and obtaining the values adjusted for the endogenous variable of the model. An auxiliary regression is then performed, regressing the difference between the squared residuals of the model and the average of the variable with the squared adjusted values. If the coefficient associated with the adjusted squared values is significant at the usual level, the null hypothesis would be rejected and there would therefore be evidence of overdispersion.

The alternative approach suggested by Wooldridge (1990) consists of carrying out an auxiliary regression on the squared standardised residuals of the Poisson model -1 and the adjusted squared values. As in the test above, if the
} 
Both models were applied for the models for the number of publications and the number of citations and, with the sole exception of the Poisson model for the number of citations and the total sample of universities, the null hypothesis that the estimation of the Poisson model is appropriate was rejected in all cases. The results that will be discussed below are those obtained from the negative binomial distribution, which are also shown in the appropriate tables.

As regards the first group of variables, and the fictitious variable related to the ownership of the university in particular, this variable has a positive sign but is not statistically significant in the vast majority of the models considered. However, in the Tobit model for the number of articles per lecturer for the average impact of publications per university, it is positive and statistically significant (although in the former case, the level of significance is 10\%). This may be explained by two reasons. These are the greater importance of quality publications for promotion in public universities, and also, as mentioned above, the recent establishment of some private universities. In fact, the fictitious variable related to the subsequent establishment of the URL is statistically significant and has a negative sign in all the models considered.

The variable "number of qualifications offered by the university" shows contradictory results. In the majority of models it appears to be insignificant, but in some cases it nevertheless appears with a positive sign and as statistically significant. A possible explanation for this positive effect could be related to the "size" of the university - the greater the number of qualifications, the higher the number of lecturers, and therefore more opportunities to publish and be quoted. It is important to note that it does not appear as a significant variable in the models for the number of citations per article (impact) (the "size effect" which would affect both the numerator and denominator would be compensated for). In this respect, the variable "students per lecturer in Economics and Business" is statistically significant at normal levels and shows the anticipated negative sign (greater teaching demands would entail lower scientific productivity) in the models for the number of articles, but not for the number of citations received or the impact. However, third cycle teaching work (measured by the number of theses read and by the number of third cycle students) has positive and significant effects in all the models considered, with the sole exception being the models for impact (although the p-value figures are very close to $10 \%)$.

A second group of potential explanatory variables is related to obtaining public financing for research. In practically all cases, the effects found are positive and significant, both with regard to Spanish projects (BEC and SEC) and European projects and the Ramón y Cajal programme.

The penultimate bloc of explanatory variables refers to the characteristics of the teaching staff at public universities (it was not possible to obtain this information for the private universities). The possible effect of the proportion of female lecturers among the teaching staff, the relative weight of tenured teaching staff and the percentage of lecturers with one or more six-year research periods out of

coefficient associated with the adjusted squared values is significant at the usual level, the null hypothesis would be rejected and there would therefore be evidence of overdispersion. 
the total teaching staff was considered while the variable related to the relative importance of women does not appear to be significant and the variable related to the percentage of tenured staff only has a negative and significant influence on the number of publications, the variable for six-year periods has a positive and significant effect on all the models. It therefore seems that the teaching staff consolidation system has a negative effect on production while the bonus payment seems to have a positive effect not only on production but also on the impact of research. This would suggest that there is "pressure" to carry out high quality research (although it must be acknowledged that the results of this variable may be subject to some problems of endogeneity due to the criteria used to recognise the six-year periods was based on publications and on the citations received).

A final group of variables consists of those related to how research is carried out in the various universities. In specific terms, the percentage of articles produced in collaboration with other researchers (co-authorships), the percentage of articles from each university published in high quality journals, and the percentage of articles produced in collaboration with researchers affiliated to institutions other than those in Spain were considered using the database mentioned above. Using the results shown in the literature, the first variable (co-authorships) was only included in the models for the number of publications and publications per author, and where the percentage of publications in high quality journals was not included. However, in the models for the number of citations and impact, the variables related to publications in high quality journals and international collaborations were considered.

The results obtained show that co-authorships have no significant effect on scientific production. Sutter and Kocher (2004) found a similar result for economics departments in American universities.

However, international collaborations have a positive and significant effect on practically all the models analysed (with the exception of the model for the number of articles by lecturer). Once again, the results are similar to those obtained by Sutter and Kocher (2004). These authors analyse the effects of collaborations with other institutions on departments economics in American universities and conclude that these collaborations have a significant impact on scientific production. It also needs to be remembered that using a gravity model, they find that factors such as distance and other variables of a geographical nature do not help to explain the reasons influencing scientific production, but that collaboration with other institutions does have a significant impact.

Finally, the results for the influence of the proportion of articles published in high quality journals show that this variable has a positive and significant effect on the impact of the publications produced but not on the number of citations received (it should be remembered that the fact that this variable appears as significant in some Poisson models is related to the existence of overdispersion). A possible explanation for this is that the work necessary to achieve publication in these journals may on average involve the production of fewer articles, and the increase in citations arising from publication 
in a higher quality/circulation journal could therefore be reduced due to the fact that fewer articles have been published.

\section{Conclusions}

Despite a significant increase in the number of publications by authors affiliated to Spanish universities in recent decades, the evidence obtained in this study clearly shows the existence of major differences between Spanish university institutions.

It was also possible to identify some of the factors influencing scientific production, productivity and the impact of Business and Economics research done by Spanish universities. In specific terms, some variables were identified as having a positive effect on the indicators produced, such as belonging to a public university, having a third cycle programme, having public financing obtained in competitive selection procedures, having a larger number of full-time researchers (like those associated with the Ramón y Cajal programme) or involvement in collaborations with international institutions. However, there are other variables which appear to have the opposite effect. Among these are a higher number of students per lecturer or a lower proportion of lecturers with recognised six-year periods.

These results can be used to deduce some implications from the point of view of scientific policy in this area. In particular, the main conclusion arising from this study is that in order to reduce the differences between Spanish universities in terms of their scientific production and its impact, it is necessary to promote quality doctorate programmes at all universities, stimulate research by providing the universities with the necessary personnel and resources, and actively encouraging international collaborations. These policies are particularly necessary in private universities, as their recent creation and their greater orientation towards teaching led to less scientific work during the period analysed.

\section{References}

Adams, J. D., Clemmons, J. R. (2006), The growing allocative inefficiency of the U.S. higher education sector, mimeo. Available at http://www.nber.org/ sewp/references.html.

CAmeron, A., Trivedi, P. (1990), Regression-based Tests for Overdispersion in the Poisson ModelJournal of Econometrics, 46: 347-364.

CAMERON, B. D. (2005), Trends in the usage of ISI bibliometric data: Uses, abuses, and implications, Libraries and the Academy, 5: 105-125.

Cherchye, L., VAnden ABeele, P. (2005), On research efficiency. A micro analysis of Dutch university research in Economics and Business Management. Research Policy, 34: 495-416.

COMBES, P., LinNEMER, L. (1999), The publication of research papers in France. An approach using citations. CERAS working paper 00-04. 
COMBES, P., LINNEMER, L. (2000), The publication of research papers in France, an approach using the quality of journals. CERAS working paper 99-13.

CONROY, M., DUSANSKY, R. (1995), The productivity of economics departments in the US: Publications in core journals. Journal of Economic Literature, 33: 1966-1971.

COUPÉ, T. (2003), Revealed performances. Worldwide rankings of economists and economics departments, 1990-2000. Journal of the European Economic Association, 1: 1309-1345.

Davis, J., Huston, J. MoOre PATterson, D. (2001), Scholarly Output of Economists: A Description of Publishing Patterns. Atlantic Economic Journal, 29: 341-349.

DUSANSKY, R., VERnON, C. (1998), Rankings of U.S. Economics Departments. Journal of Economic Perspectives, 12: 157-170.

EhrenberG, R. G. (2003), Studying Ourselves: The Academic Labor Market, Journal of Labor Economics, 21: 267-287.

FARIA, J. R. (2001), Rent seeking in academia: The consultancy disease. The American Economist, 45: 69-74.

FoX, K. J., MilbouRne, R. (1999), What determines research output of academic economists?, Economic Record, 75: 256-267.

FUSFELD, D. R. (1956), The origins of the contributors to the AER during the 50s. American Economic Review, 46: 642-644.

García, P., Lafuente, A., Montañés, A., SanZ, F. (1999a), Producción científica en economía según publicaciones en revistas internacionales: el caso de España. Papeles de Economía Española, 81: 49-57.

García, P., MontañÉs, A., SANZ, F. (1999b) La investigación en economía en España: Mercado nacional ¿versus? Mercado internacional. Revista de Economía Aplicada, 20: 167-187.

Huettner, D. A., ClARK, W. (1997), Comparative research productivity measures for Economics Departments. Journal of Economic Education, 28: 272-278.

JOHNES, G. (1988), Determinants of research output in economics departments in British-Universities, Research Policy, 17: 171-178.

Kalaitzidakis, P., Mamuneas, T., Stengos, T. (2003), Rankings of Academic Journals and Institutions in Economics. Journal of the European Economics Association, 1: 1346-1366.

Kalaitzidakis, P., Mamuneas, T., Savvides, A., Stengos T. (2004), Research spillovers among European and North-American economics departments. Economics of Education Review, 23: 191-202.

LuBrano, M. (2001), Ranking Economic Departments in Belgium, France and Spain: partial results from a more general report. http://durandal.cnrs-mrs.fr/PP/lubrano/rankings/ranking.htm.

MARTínez CABrera, M. (2000), Análisis de la eficiencia productiva de las instituciones de educación superior. Papeles de Economía Española, 86: 179-191. 
MAske, K. L., DuRden, G. C., GAYNOR, P. (2003), Determinants of scholarly productivity among male and females economists. Economic Inquiry, 41: 555-564.

MeIN, D. G. (2002), Research productivity and career status. Applied Economics Letters, 9: 809-815.

MoyA-ANEGON, F. (DIR.) (2005), Indicadores bibliométricos de la actividad científica española, FECYT, Madrid.

SANZ, E., GarcíA, C., GarcíA, A., Modrego A. (1999), La investigación española en Economía a través de las publicaciones nacionales e internacionales en el período 1990-1995. Revista de Economía Aplicada, 20: 113-137.

SANZ MENÉnDEZ, L. (1995), Research actors and the state: research evaluation and evaluation of science and technology policies in Spain. Research Evaluation, 5: 79-88.

SANZ MENÉNDEZ, L. (2003), La investigación en la universidad española: la financiación competitiva de la investigación, con especial referencia a las Ciencias Sociales y Económicas. Documento de Trabajo Unidad de Políticas Comparadas (CSIC) 03-06.

Spangenbert, J. F. A., BreemhaAr, B., Nijhuis, F., AlfenaAr, W. (1990a), Some incentives and constraints of scientific performance in Economics. 1. Predictor-criterion relations, Scientometrics, 18: 241-268.

Spangenbert, J. F. A., BreemhaAr, B., Nijhuis, F., AlfenaAr, W. (1990b), Some incentives and constraints of scientific performance in Economics. 2. Validity and sensitivity analysis, Scientometrics, 18: 269-279.

SutTer, M., Kocher, M. (2004), Patterns of co-authorship among economics departments in the USA. Applied Economics, 36: 327-333.

TAYLOR, S.W., FENDER, B.F., BURKe, K.G., (2006), Unravelling the academia productivity of economists: The opportunity costs of teaching and service, Southern Economic Journal, 72: 846-859.

Tombazos, C. G. (2005), A revisionist perspective of European research in Economics. European Economic Review, 49: 251-277.

Verbeek, A., Debackere, K., Luwel, M., ZimmermanN, E. (2002), Measuring progress and evolution in science and technology - I: The multiple uses of bibliometric indicators, International Journal of Management Reviews, 2: 179-211.

VILlAR, A. (2003), La evaluación de la investigación en economía. Revista Valenciana de Economía y Hacienda, 8. 97-133.

Wooldridge, J. (1990), Quasi-Likelihood Methods for Count Data, in: Pesaran, H., Schmidt, P. (eds.), Handbook of Applied Econometrics, Volume 2, Blackwell, pp. 352-406. 


\section{Acknowledgments}

Authors wish to thank an anonymous referee for his/her helpful suggestions and comments. The usual disclaimer applies. The results presented in this study were obtained within the framework of the projects "Research in Economic and Business Sciences: a bibliometric analysis" (EA20040102) and "The impact of Spanish scientific publications on Economics and Business: A bibliometric analysis" (EA2005-0142), within the Studies and Analysis programme of the Ministry of Education and Science. 


\section{TABLES AND FIGURES}

Table 1. Public universities that taught Economics or Business Administration and Management courses in the academic year 2004/2005 (continues)

\begin{tabular}{lcc}
\hline & Economics & Business \\
\hline A Coruña & $\mathrm{X}$ & $\mathrm{X}$ \\
Alcalá & $\mathrm{X}$ & $\mathrm{X}$ \\
Alicante & $\mathrm{X}$ & $\mathrm{X}$ \\
Almería & & $\mathrm{X}$ \\
Autònoma de Barcelona & $\mathrm{X}$ & $\mathrm{X}$ \\
Autónoma de Madrid & $\mathrm{X}$ & $\mathrm{X}$ \\
Barcelona & $\mathrm{X}$ & $\mathrm{X}$ \\
Burgos & & $\mathrm{X}$ \\
Cádiz & & $\mathrm{X}$ \\
Cantabria & $\mathrm{X}$ & $\mathrm{X}$ \\
Carlos III de Madrid & $\mathrm{X}$ & $\mathrm{X}$ \\
Castilla-La Mancha & $\mathrm{X}$ & $\mathrm{X}$ \\
Complutense de Madrid & $\mathrm{X}$ & $\mathrm{X}$ \\
Córdoba & & $\mathrm{X}$ \\
Extremadura & $\mathrm{X}$ & $\mathrm{X}$ \\
Girona & $\mathrm{X}$ & $\mathrm{X}$ \\
Granada & $\mathrm{X}$ & $\mathrm{X}$ \\
Huelva & $\mathrm{X}$ & $\mathrm{X}$ \\
Illes Balears & $\mathrm{X}$ & $\mathrm{X}$ \\
Internacional de Andalucía & $\mathrm{X}$ \\
Internacional Menéndez Pelayo & $\mathrm{X}$ \\
Jaén & $\mathrm{X}$ \\
Jaume I de Castellón & $\mathrm{X}$ \\
La Laguna & $\mathrm{X}$ & $\mathrm{X}$ \\
La Rioja & $\mathrm{X}$ \\
Las Palmas de Gran Canaria & & $\mathrm{X}$ \\
León & & $\mathrm{X}$ \\
Lleida & & $\mathrm{X}$ \\
Málaga & & $\mathrm{X}$ \\
Miguel Hernández de Elche & & $\mathrm{X}$ \\
Murcia & & $\mathrm{X}$ \\
Nacional de Educación a Distancia & \\
Oviedo & & $\mathrm{X}$ \\
Pablo de Olavide & & $\mathrm{X}$ \\
\hline & & $\mathrm{X}$ \\
Pasco/Euskal Herriko Unibertsitatea & $\mathrm{X}$ \\
\hline
\end{tabular}


Table 1. Public universities that taught Economics or Business Administration and Management courses in the academic year 2004/2005 (continuation)

\begin{tabular}{lcc}
\hline & Economics & Business \\
\hline Politécnica de Cartagena & & $\mathrm{X}$ \\
Politécnica de Valencia & & $\mathrm{X}$ \\
Pompeu Fabra & $\mathrm{X}$ & $\mathrm{X}$ \\
Pública de Navarra & $\mathrm{X}$ & $\mathrm{X}$ \\
Rey Juan Carlos & $\mathrm{X}$ & $\mathrm{X}$ \\
Rovira i Virgili & $\mathrm{X}$ & $\mathrm{X}$ \\
Salamanca & $\mathrm{X}$ & $\mathrm{X}$ \\
Santiago de Compostela & $\mathrm{X}$ & $\mathrm{X}$ \\
Sevilla & $\mathrm{X}$ & $\mathrm{X}$ \\
Valencia Estudi General & $\mathrm{X}$ & $\mathrm{X}$ \\
Valladolid & $\mathrm{X}$ & $\mathrm{X}$ \\
Vigo & $\mathrm{X}$ & $\mathrm{X}$ \\
Zaragoza & $\mathrm{X}$ & $\mathrm{X}$ \\
\hline
\end{tabular}

Table 2. Private universities supported by the Catholic Church that taught Economics or Business Administration and Management courses in the academic year 2004/2005

\begin{tabular}{lcc}
\hline & Economics & Business \\
\hline Católica de Ávila & $\mathrm{X}$ & $\mathrm{X}$ \\
Católica de Valencia San Vicente Mártir & & $\mathrm{X}$ \\
Católica San Antonio & & $\mathrm{X}$ \\
Deusto & & $\mathrm{X}$ \\
Navarra & $\mathrm{X}$ & $\mathrm{X}$ \\
Pontificia Comillas & & $\mathrm{X}$ \\
Pontificia de Salamanca & & $\mathrm{X}$ \\
\hline
\end{tabular}


Table 3. Private universities that taught Economics or Business Administration and Management courses in the academic year 2004/2005

\begin{tabular}{lcc}
\hline & Economics & Business \\
\hline Abat Oliba Ceu & $\mathrm{X}$ & $\mathrm{X}$ \\
Alfonso X el Sabio & & $\mathrm{X}$ \\
Antonio de Nebrija & & $\mathrm{X}$ \\
Camilo José Cela & & \\
Cardenal Herrera-Ceu & $\mathrm{X}$ & $\mathrm{X}$ \\
Europea de Madrid & & \\
Europea Miguel de Cervantes & $\mathrm{X}$ & $\mathrm{X}$ \\
Francisco de Vitoria & & $\mathrm{X}$ \\
Internacional de Catalunya & & $\mathrm{X}$ \\
Mondragón Unibertsitatea & & $\mathrm{X}$ \\
Oberta ce Catalunya & & $\mathrm{X}$ \\
Ramón Llull & & \\
S.E.K. & $\mathrm{X}$ & $\mathrm{X}$ \\
San Pablo C.E.U. & & $\mathrm{X}$ \\
Vic & & \\
\hline
\end{tabular}

Table 4. Relative importance Economics or Business Administration and Management studies

\begin{tabular}{lccc}
\hline & Total & Economics & Business \\
\hline Public universities & 50 & 33 & 46 \\
Private universities supported by the Catholic Church & 7 & 2 & 7 \\
Private universities & 15 & 4 & 12 \\
Total & 72 & 39 & 65 \\
\hline
\end{tabular}


Table 5. Number of published articles, citations received and citations per article by Spanish universities between 1994 and 2004 (continues)

\begin{tabular}{|c|c|c|c|c|}
\hline & Articles & Articles/lecturer & Citations & Citations/article \\
\hline Pompeu Fabra & 280 & 0.33 & 2193 & 7.83 \\
\hline Miguel Hernández de Elche & 11 & 0.01 & 79 & 7.18 \\
\hline Alcalá de Henares & 39 & 0.02 & 171 & 4.38 \\
\hline Carlos III De Madrid & 283 & 0.24 & 1181 & 4.17 \\
\hline Córdoba & 2 & 0.00 & 8 & 4.00 \\
\hline Autònoma de Barcelona & 218 & 0.07 & 832 & 3.82 \\
\hline Barcelona & 137 & 0.03 & 494 & 3.61 \\
\hline Alacant & 142 & 0.08 & 450 & 3.17 \\
\hline Sevilla & 35 & 0.01 & 101 & 2.89 \\
\hline Euskal Herriko Unibertsitatea & 130 & 0.03 & 375 & 2.88 \\
\hline Salamanca & 39 & 0.02 & 111 & 2.85 \\
\hline Navarra & 78 & 0.03 & 217 & 2.78 \\
\hline Autónoma de Madrid & 49 & 0.02 & 134 & 2.73 \\
\hline Granada & 25 & 0.01 & 67 & 2.68 \\
\hline Málaga & 30 & 0.02 & 80 & 2.67 \\
\hline Nacional de Educación a Distancia (UNED) & 20 & 0.00 & 51 & 2.55 \\
\hline Santiago de Compostela & 34 & 0.02 & 86 & 2.53 \\
\hline Lleida & 6 & 0.01 & 14 & 2.33 \\
\hline Complutense de Madrid & 140 & 0.02 & 316 & 2.26 \\
\hline La Laguna & 32 & 0.02 & 70 & 2.19 \\
\hline Girona & 24 & 0.03 & 50 & 2.08 \\
\hline Almería & 7 & 0.01 & 14 & 2.00 \\
\hline Valencia & 170 & 0.05 & 333 & 1.96 \\
\hline Valladolid & 33 & 0.01 & 63 & 1.91 \\
\hline Publica de Navarra & 69 & 0.09 & 131 & 1.90 \\
\hline La Rioja & 7 & 0.02 & 12 & 1.71 \\
\hline Zaragoza & 121 & 0.04 & 198 & 1.64 \\
\hline Oviedo & 56 & 0.03 & 90 & 1.61 \\
\hline Pontificia Comillas & 6 & 0.01 & 9 & 1.50 \\
\hline San Pablo C.E.U. & 4 & 0.00 & 6 & 1.50 \\
\hline Castilla La Mancha & 9 & 0.00 & 13 & 1.44 \\
\hline Cádiz & 14 & 0.01 & 20 & 1.43 \\
\hline Extremadura & 20 & 0.01 & 28 & 1.40 \\
\hline
\end{tabular}


Table 5. Number of published articles. citations received and citations per article by Spanish universities between 1994 and 2004 (continuation)

\begin{tabular}{lcccc} 
& Articles & Articles/lecturer & Citations & Citations/article \\
\hline Vigo & 69 & 0.04 & 84 & 1.22 \\
A Coruña & 15 & 0.01 & 17 & 1.13 \\
Europea de Madrid - CEES & 10 & 0.02 & 11 & 1.10 \\
Las Palmas de Gran Canaria & 51 & 0.03 & 52 & 1.02 \\
Burgos & 3 & 0.00 & 3 & 1.00 \\
Deusto & 2 & 0.00 & 2 & 1.00 \\
Huelva & 2 & 0.00 & 2 & 1.00 \\
Cantabria & 21 & 0.02 & 21 & 1.00 \\
Politecnica de Valencia & 13 & 0.01 & 13 & 1.00 \\
Illes Balears & 16 & 0.02 & 15 & 0.94 \\
Rovira i Virgili & 13 & 0.01 & 11 & 0.85 \\
Jaén & 6 & 0.01 & 5 & 0.83 \\
Politécnica de Cartagena & 11 & 0.02 & 9 & 0.82 \\
Murcia & 45 & 0.02 & 36 & 0.80 \\
Jaume I de Castelló & 55 & 0.06 & 39 & 0.71 \\
Pablo de Olavide & 17 & 0.04 & 10 & 0.59 \\
Francisco de Vitoria & 2 & 0.00 & 1 & 0.50 \\
León & 5 & 0.01 & 1 & 0.20 \\
Alfonso X El Sabio & 0 & 0.00 & 0 & 0.00 \\
Antonio de Nebrija & 0 & 0.00 & 0 & 0.00 \\
Cardenal Herrera - Ceu & 0 & 0.00 & 0 & 0.00 \\
Católica de Ávila & 0 & 0.00 & 0 & 0.00 \\
Católica San Antonio de Murcia & 0 & 0.00 & 0 & 0.00 \\
Pontificia de Salamanca & 0.00 & 0 & 0.00 \\
Rey Juan Carlos & 0.00 & 0 & 0.00 \\
Vic & 0.00 & 0 & 0.00 \\
Internacional de Catalunya & 0.00 & 0 & 0.00 \\
Oberta de Catalunya & 0.00 & 0.00 \\
Ramón Llull & 0 & & 0.00 \\
\hline Total (or average) & 0.00 & 3.17 \\
\hline & 0 & 0.00 & \\
\hline
\end{tabular}


Table 6. Estimation results of Poisson and Negative Binomial models of articles by university between 1994 and 2004

\begin{tabular}{|c|c|c|c|c|c|c|c|c|}
\hline \multirow{3}{*}{$\begin{array}{l}\text { Models for the number of articles } \\
\text { published between } 1994 \text { and } 2004\end{array}$} & \multicolumn{4}{|c|}{ Public and Private universities } & \multicolumn{4}{|c|}{ Public universities } \\
\hline & \multicolumn{2}{|c|}{ Poisson } & \multicolumn{2}{|c|}{ Negative Binomial } & \multicolumn{2}{|c|}{ Poisson } & \multicolumn{2}{|c|}{ Negative Binomial } \\
\hline & Coefficient & P-value & Coefficient & P-value & Coefficient & P-value & Coefficient & P-value \\
\hline Intercept & 1.493 & 0.000 & 0.952 & 0.053 & 2.506 & 0.000 & 3.735 & 0.016 \\
\hline Public & 0.371 & 0.025 & 0.336 & 0.295 & & & & \\
\hline Created after URL & -0.673 & 0.000 & -0.581 & 0.009 & & & & \\
\hline Number of studies & -0.001 & 0.706 & -0.001 & 0.883 & 0.007 & 0.082 & 0.013 & 0.207 \\
\hline Students by lecturer in the field of Economics or Business & & & & & -0.016 & 0.000 & -0.026 & 0.006 \\
\hline Share of students in Economics or Business & 2.990 & 0.000 & 2.274 & 0.090 & 5.188 & 0.000 & 4.278 & 0.062 \\
\hline Ph. D. Thesis in Economics or Business & 0.002 & 0.000 & 0.005 & 0.000 & & & & \\
\hline Ph. D. students in Economics or Business & & & & & 0.000 & 0.028 & 0.000 & 0.382 \\
\hline BEC projects & 1.976 & 0.000 & 1.858 & 0.030 & 0.657 & 0.013 & 0.714 & 0.288 \\
\hline SEC projects & 1.562 & 0.000 & 1.347 & 0.064 & 1.802 & 0.000 & 1.932 & 0.000 \\
\hline European projects & 0.011 & 0.391 & 0.001 & 0.988 & 0.026 & 0.017 & 0.017 & 0.560 \\
\hline Ramón y Cajal & 0.013 & 0.445 & 0.089 & 0.110 & 0.068 & 0.010 & 0.097 & 0.144 \\
\hline Proportion of female lecturers among the teaching staff & & & & & 1.892 & 0.129 & 0.446 & 0.827 \\
\hline Relative weight of tenured teaching staff & & & & & -0.400 & 0.514 & -2.044 & 0.251 \\
\hline Percentage of lecturers with one or more six-year research & & & & & & & & \\
\hline periods out of the total teaching staff & & & & & 2.392 & 0.003 & 4.111 & 0.062 \\
\hline Relative share of coauthored articles & 0.112 & 0.723 & 0.646 & 0.150 & -1.797 & 0.120 & -1.864 & 0.184 \\
\hline Relative share of internationally coauthored articles & 0.871 & 0.030 & 1.305 & 0.083 & -0.146 & 0.786 & -0.203 & 0.850 \\
\hline Overdispersion test (Cameron and Trivedi, 1990) & 0.030 & 0.021 & & & 0.040 & 0.001 & & \\
\hline Overdispersion test (Wooldridge, 1990) & 0.116 & 0.084 & & & 0.104 & 0.002 & & \\
\hline Pseudo $R^{2}$ & \multicolumn{2}{|c|}{0.773} & \multicolumn{2}{|c|}{0.780} & 0.78 & & \multicolumn{2}{|c|}{0.797} \\
\hline Observations & \multicolumn{2}{|c|}{62} & \multicolumn{2}{|c|}{62} & 44 & & \multicolumn{2}{|c|}{44} \\
\hline
\end{tabular}


Table 7. Estimation results of Tobit models for the number of articles per lecturer by university between 1994 and 2004

\begin{tabular}{|c|c|c|c|c|}
\hline \multirow{2}{*}{$\begin{array}{l}\text { Models for the number of articles } \\
\text { by lecturer between } 1994 \text { and } 2004\end{array}$} & \multicolumn{2}{|c|}{$\begin{array}{c}\text { Public and private universities } \\
\text { Tobit }\end{array}$} & \multicolumn{2}{|c|}{$\begin{array}{c}\text { Public universities } \\
\text { Tobit }\end{array}$} \\
\hline & Coefficient & P-value & Coefficient & P-value \\
\hline Intercept & -6.902 & 0.481 & 18.093 & 0.538 \\
\hline Public & 13.110 & 0.095 & & \\
\hline Created after URL & 3.311 & 0.412 & & \\
\hline Number of studies & 0.416 & 0.051 & 0.515 & 0.037 \\
\hline Students by lecturer & 0.648 & 0.261 & & \\
\hline Students by lecturer in the field of Economics or Business & & & 0.041 & 0.859 \\
\hline Share of students in Economics or Business & 1.726 & 0.030 & 28.614 & 0.647 \\
\hline BEC projects & 24.176 & 0.126 & 17.476 & 0.381 \\
\hline SEC projects & 73.31 & 0.000 & 84.464 & 0.000 \\
\hline European projects & 1.682 & 0.057 & 1.367 & 0.104 \\
\hline Ramón y Cajal & 17.683 & 0.000 & 17.359 & 0.000 \\
\hline Proportion of female lecturers among the teaching staff & & & 8.487 & 0.871 \\
\hline Relative weight of tenured teaching staff & & & -0.221 & 0.996 \\
\hline \multicolumn{5}{|l|}{ Percentage of lecturers with one or more six-year research } \\
\hline periods out of the total teaching staff & & & -12.917 & 0.829 \\
\hline Relative share of coauthored articles & -43.651 & 0.211 & -57.468 & 0.174 \\
\hline Relative share of internationally coauthored articles & 22.975 & 0.167 & 11.105 & 0.716 \\
\hline $\mathrm{R}^{2}$ & \multicolumn{2}{|c|}{0.910} & \multicolumn{2}{|c|}{0.911} \\
\hline Observations & \multicolumn{2}{|c|}{62} & \multicolumn{2}{|c|}{44} \\
\hline
\end{tabular}


Table 8. Estimation results of Poission and Negative Binominal models for the number of citations by university among 1994 and 2004

\begin{tabular}{|c|c|c|c|c|c|c|c|c|}
\hline \multirow{3}{*}{$\begin{array}{l}\text { Models for the number of citations } \\
\text { received between } 1994 \text { and } 2004\end{array}$} & \multicolumn{4}{|c|}{ Public and private universities } & \multicolumn{4}{|c|}{ Public universities } \\
\hline & \multicolumn{2}{|c|}{ Poisson } & \multicolumn{2}{|c|}{ Negative Binomial } & \multicolumn{2}{|c|}{ Poisson } & \multicolumn{2}{|c|}{ Negative Binomial } \\
\hline & Coefficient & P-value & Coefficient & P-value & Coefficient & P-value & Coefficient & P-value \\
\hline Intercept & 2.451 & 0.000 & 1.880 & 0.000 & 2.368 & 0.000 & 1.993 & 0.000 \\
\hline Public & 0.088 & 0.419 & 0.122 & 0.448 & & & & \\
\hline Created after URL & -1.226 & 0.000 & -0.859 & 0.000 & & & & \\
\hline Number of studies & 0.001 & 0.5280 & 0.001 & 0.961 & 0.033 & 0.000 & 0.025 & 0.000 \\
\hline Students by lecturer & & & & & 0.072 & 0.103 & 0.031 & 0.102 \\
\hline Students by lecturer in the field of Economics or Business & 2.594 & 0.000 & 1.649 & 0.036 & -0.048 & 0.000 & -0.033 & 0.000 \\
\hline Ph. D. Thesis in Economics or Business & 0.002 & 0.000 & 0.005 & 0.000 & 9.072 & 0.000 & 6.686 & 0.000 \\
\hline Ph. D. students in Economics or Business & & & & & 0.000 & 0.000 & 0.000 & 0.000 \\
\hline BEC projects & 1.329 & 0.000 & 1.094 & 0.003 & 2.857 & 0.000 & 1.164 & 0.000 \\
\hline SEC projects & 2.988 & 0.000 & 2.229 & 0.000 & 2.569 & 0.000 & 2.506 & 0.000 \\
\hline European projects & 0.043 & 0.000 & 0.022 & 0.322 & & & & \\
\hline Ramón y Cajal & 0.136 & 0.000 & 0.155 & 0.000 & 0.093 & 0.000 & 0.181 & 0.000 \\
\hline Proportion of female lecturers among the teaching staff & & & & & -3.968 & 0.000 & -1.718 & 0.071 \\
\hline Relative weight of tenured teaching staff & & & & & -3.422 & 0.000 & -2.698 & 0.005 \\
\hline Percentage of lecturers with one or more six-year research & & & & & & & & \\
\hline periods out of the total teaching staff & & & & & 3.874 & 0.000 & 5.281 & 0.000 \\
\hline Relative share of coauthored articles & -4.123 & 0.000 & 0.852 & 0.274 & -7.622 & 0.000 & -4.531 & 0.101 \\
\hline Relative share of internationally coauthored articles & 2.551 & 0.000 & 3.314 & 0.000 & 3.814 & 0.000 & 2.621 & 0.000 \\
\hline Overdispersion test (Cameron and Trivedi, 1990) & 0.002 & 0.162 & & & 0.003 & 0.018 & & \\
\hline Overdispersion test (Wooldridge, 1990) & 0.025 & 0.474 & & & 0.015 & 0.253 & & \\
\hline Pseudo $R^{2}$ & \multicolumn{2}{|c|}{0.904} & \multicolumn{2}{|c|}{0.944} & \multicolumn{2}{|c|}{0.938} & \multicolumn{2}{|c|}{0.971} \\
\hline Observations & \multicolumn{2}{|c|}{62} & \multicolumn{2}{|c|}{62} & \multicolumn{2}{|c|}{44} & \multicolumn{2}{|c|}{44} \\
\hline
\end{tabular}


Table 9. Estimation results of Tobit models for the average impact by university between 1994 and 2004

\begin{tabular}{|c|c|c|c|c|}
\hline \multirow{3}{*}{$\begin{array}{l}\text { Models for the number of citations per article } \\
\text { between } 1994 \text { and } 2004\end{array}$} & \multicolumn{4}{|c|}{ Tobit models } \\
\hline & \multicolumn{2}{|c|}{ Public and private universities } & \multicolumn{2}{|c|}{ Public universities } \\
\hline & Coefficient & P-value & Coefficient & P-value \\
\hline Intercept & 0.027 & 0.967 & 1.642 & 0.322 \\
\hline Public & 1.110 & 0.037 & & \\
\hline Created after URL & -0.992 & 0.019 & & \\
\hline Number of studies & -0.008 & 0.556 & 0.004 & 0.769 \\
\hline Students by lecturer & 0.043 & 0.261 & 0.004 & 0.745 \\
\hline Students by lecturer in the field of Economics or Business & & & -4.497 & 0.254 \\
\hline Ph. D. Thesis in Economics or Business & 0.000 & 0.993 & & \\
\hline Ph. D. students in Economics or Business & & & 0.000 & 0.587 \\
\hline BEC projects & -1.855 & 0.072 & -1.708 & 0.128 \\
\hline SEC projects & 2.151 & 0.107 & 1.327 & 0.326 \\
\hline European projects & 0.083 & 0.148 & 0.043 & 0.435 \\
\hline Ramón y Cajal & 0.342 & 0.001 & 0.433 & 0.001 \\
\hline Proportion of female lecturers among the teaching staff & & & 0.758 & 0.802 \\
\hline Relative weight of tenured teaching staff & & & -3.311 & 0.261 \\
\hline \multicolumn{5}{|l|}{ Percentage of lecturers with one or more six-year research } \\
\hline periods out of the total teaching staff & & & 4.825 & 0.009 \\
\hline Relative share of coauthored articles & 1.512 & 0.506 & 0.353 & 0.881 \\
\hline Relative share of internationally coauthored articles & 3.502 & 0.002 & 3.003 & 0.079 \\
\hline $\mathrm{R}^{2}$ & \multicolumn{2}{|c|}{0.604} & \multicolumn{2}{|c|}{0.611} \\
\hline Observations & \multicolumn{2}{|c|}{62} & \multicolumn{2}{|c|}{44} \\
\hline
\end{tabular}


Figure 1. Lorenz curve for the number of published articles and citations received by university between 1994 and 2004

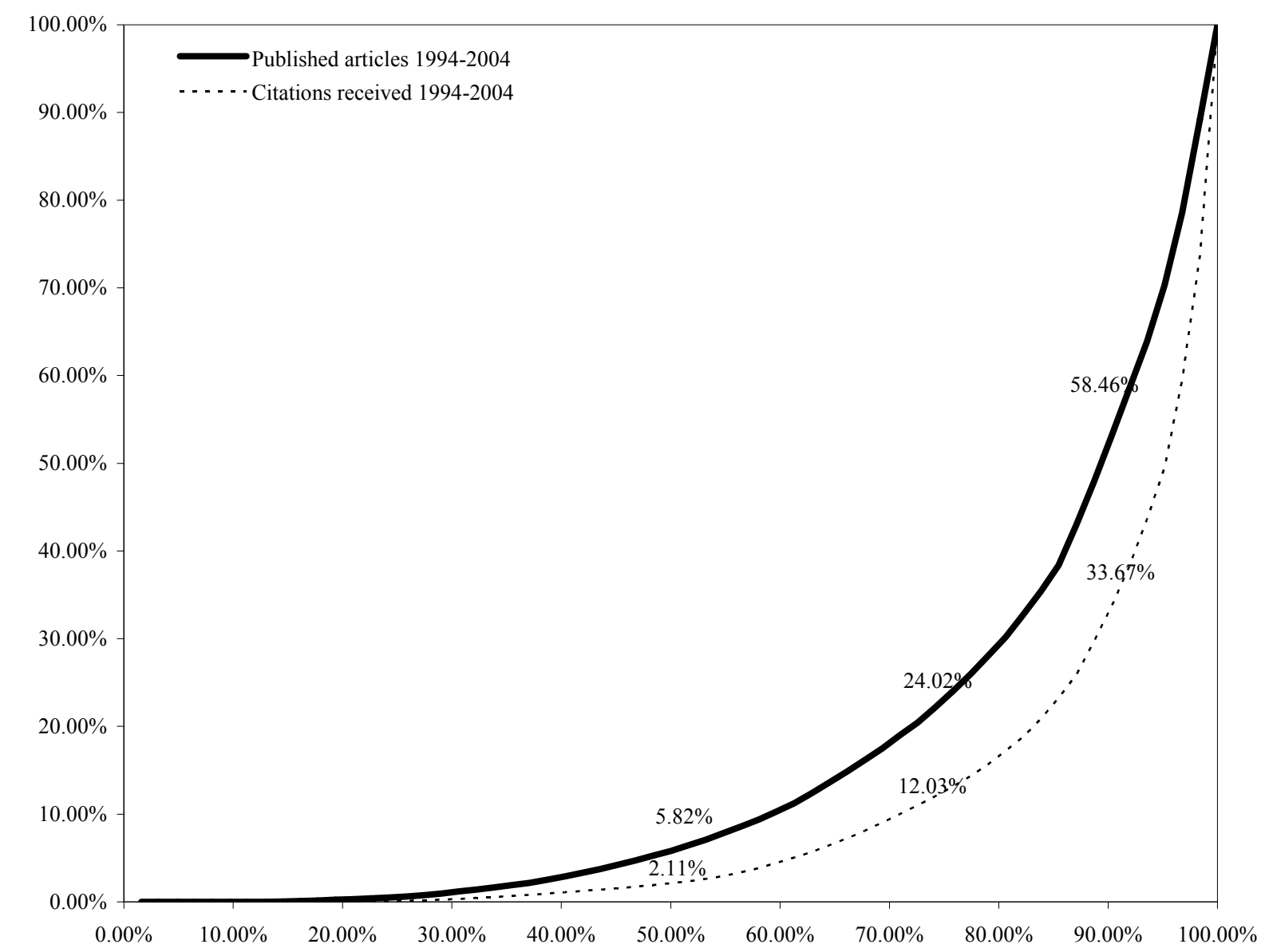

